\title{
VARIABILIDADE GENÉTICA DE POPULAÇÕES DE FAVA D'ANTA (Dimorphandra mollis) DA REGIÃO NORTE DO ESTADO DE MINAS GERAIS ${ }^{1}$
}

\author{
Dario Alves de Oliveira ${ }^{2}$, Márcia Fabiana Barbosa de Paula ${ }^{3}$, Marcio Antonio Silva Pimenta ${ }^{2}$, Rodrigo \\ Fagundes Braga ${ }^{4}$, Maria Fernanda Maia Ferreira ${ }^{4}$ e Luana Alves Rodrigues ${ }^{4}$
}

\begin{abstract}
RESUMO - Fava d'anta (Dimorphandra mollis Benth) é uma planta nativa do Cerrado brasileiro utilizada na extração da rutina, quercetina e ramnose, produtos usados nas indústrias farmacêuticas e de cosméticos. O norte do Estado de Minas Gerais produz cerca de 23\% da rutina nacional. A obtenção dessa espécie tem sido de forma predatória pelos extrativistas, e estudos da variabilidade genética dessas populações podem fornecer subsídios para estratégias de conservação e manutenção da espécie. O objetivo deste trabalho foi analisar a diversidade genética dessa planta por meio da técnica de RAPD. Para isso, foram coletadas folhas jovens de fava d'anta em sete localidades diferentes (Januária, Patis, Mirabela, Lontra, CAA, Jequitaí e Morro Alto) da região Norte de Minas Gerais. Nessa análise, testaram-se 43 primers. A análise de variância molecular (AMOVA) indicou que $10,3 \%$ e $89,7 \%$ da variação genética foi distribuída entre e dentro das populações, respectivamente. A diversidade genética de Nei ( $\left.\hat{H}_{e}\right)$ variou de 0,1736 (população de Morro Alto) a 0,2867 (população de Mirabela). Já a análise genética permitiu a construção de um dendrograma com formação de grupos distintos, cujas informações poderão ser utilizadas na criação de um banco de germoplasma e contribuir para a preservação da espécie.
\end{abstract}

Palavras-chave: Fava d'anta, variabilidade genética e RAPD.

\section{GENETIC VARIABILITY OF FAVA D'ANTA (Dimorphandra mollis) POPULATIONS INE NORTHERN MINAS GERAIS}

\begin{abstract}
Fava D'anta (Dimorphandra mollis Benth) is a native plant of the Brazilian open pasture used in the extraction of the active principles rutin, quercetin and ramnose, products used in the pharmaceutical and cosmetic industries. The exploitation of the fava d'anta for the extraction of these principles has been carried out through predatory exploration, and the study of the genetic variability could be important to provide strategies of conservation and maintenance of the species. The objective of this work was to analyze the genetic diversity of this species by means of the RAPD technique. Young fava d'anta leaves were harvested in seven localities (Januária, Patis, Mirabela, Lontra, CAA, Jequitaí and Morro Alto) in northern Minas; 43 primers were tested to analyze genetic diversity. The analysis of molecular variance (AMOVA) showed that $10.3 \%$ and $89.7 \%$ of the genetic variation was distributed among and within populations, respectively. Genetic diversity $\left(\hat{\mathrm{H}}_{e}\right)$ ranged from 0.1736 (Morro Alto) to 0.2867 (Mirabela). Genetic analysis allowed the construction of a dendrogram with distinct groups. The information obtained could be used in the construction of a germplasm bank to contribute for the preservation of the species.
\end{abstract}

Keywords: Fava d'anta, genetic variability and RAPD.

\footnotetext{
${ }^{1}$ Recebido em 02.03.2007 e aceito para publicação em 20.02.2008.

${ }^{2}$ Departamento de Biologia Geral da Universidade Estadual de Montes Claros (Unimontes). E-mail: <dario.oliveira@ unimontes.br> e<marcio.pimenta@unimontes.br>.

${ }^{3}$ Programa de Pós-Graduação em Biotecnologia Vegetal da Universidade Federal de Lavras (UFLA). E-mail: $<$ fabianadpaula@yahoo.com.br>.

${ }^{4}$ Programa de Pós-Graduação em Entomologia da UFLA. E-mail: <rodrigo.fagundes@ yahoo.com.br>.

${ }^{5}$ Acadêmica do Curso de Ciências Biológicas da Unimontes. E-mail: <ferreiramfm@ yahoo.com.br>.

${ }^{6}$ Programa de Pós-Graduação em Genética e Biologia Molecular da Universidade Estadual de Londrina (UEL). E-mail: <lualves13@yahoo.com.br>.
} 


\section{INTRODUÇÃO}

A fava d'anta (Dimorphandra mollis Benth.) é uma planta da família das leguminosas, de ocorrência no Cerrado e semi-árido do Centro-Oeste, Nordeste e Norte do Estado de Minas Gerais, que produz um metabólito secundário conhecido como rutina. A rutina, largamente utilizada na indústria farmacêutica e de cosméticos, possui propriedades múltiplas, como aumentar a absorção de vitamina $\mathrm{C}$ pelo organismo, atuar como oxidante na prevenção de radicais livres, auxiliar o controle da hipertensão arterial, aumentar a resistência dos vasos capilares prevenindo a calvície, auxiliar a prevenção de hemorróidas e possuir ação diurética, entre outras (YOKOZAWA et al., 1997).

Segundo Giuliano et al. (2005), a fava d'anta é uma espécie que possui alto valor econômico. Os maiores compradores de fava d' anta são a Bélgica, Alemanha, Japão e Estados Unidos. O mercado de rutina, hoje estável, tende a se expandir, porque a produção atual da matéria-prima só atende a $60 \%$ da demanda mundial ( 2 mil t/ano). A fava d' anta responde por cerca de $50 \%$ da produção mundial de rutina, cabendo o restante à espécie chinesa Sophora japonica. O Estado de Minas Gerais está entre os que mais extraem a fava, contribuindo com 23\% da produção nacional (GOMES, 1998).

O extrativismo predatório da fava d'anta está desestabilizando os ecossistemas e causando o deterioramento da diversidade genética da espécie. Segundo Lacerda e Kageyama (2003), o desenvolvimento de estratégias para a conservação genética de uma espécie passa pelo estudo da distribuição da variabilidade genética entre e dentro de suas populações. As características morfológicas são muito utilizadas para a caracterização de uma espécie, mas os marcadores moleculares fornecem uma abordagem mais específica de cada indivíduo e são muito mais eficientes para a determinação da variabilidade genética, por analisarem diretamente o material genético (YANAKA et al., 2005).

Entre os marcadores moleculares baseados em PCR (Polymerase Chain Reaction), a técnica RAPD (Random Amplified Polymorfhic DNA) tem sido mais utilizada na análise da diversidade genética de populações naturais, populações de melhoramento e em acessos de bancos de germoplasma, por ser considerada de custo mais baixo (FERREIRAe GRATTAPAGLIA, 1998). Outra vantagem da técnica RAPD é que os primers utilizados podem encontrar, aleatoriamente, regiões de homologia no DNA e, portanto, não necessita do conhecimento prévio de seqüências do genoma a ser analisado (CAIXETA et al., 2003).

O objetivo deste trabalho foi avaliar a variabilidade genética em populações de fava d' anta (Dimorphandra mollis Benth.) coletadas em diferentes localidades da região Norte do Estado de Minas Gerais.

\section{MATERIAL E MÉTODOS}

\section{a) Material Vegetal}

Folhas jovens de fava d'anta foram coletadas de 44 indivíduos provenientes de sete localidades da região Norte do Estado de Minas Gerais: Montes Claros (Centro de Agricultura Alternativa - CAA e comunidade de Morro Alto) (16 $25^{\circ}$ ' S e $\left.44^{\circ} 02^{\prime} \mathrm{W}\right)$, Jequitaí (17 $16^{\circ} 16^{\prime} \mathrm{S}$

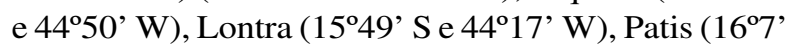

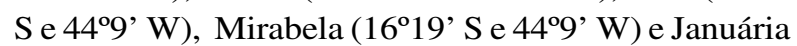
(15'29' S e 4446' W).

Para a obtenção do material vegetal foram coletadas folhas jovens de cinco indivíduos da região de Januária, oito de Patis, sete de Mirabela, 10 de Lontra, seis do Centro de Agricultura Alternativa-CAA, cinco de Jequitaí e três da região de Morro Alto, totalizando 44 indivíduos (Quadro 1).

\section{b) Extração e quantificação do DNA}

A extração do DNA foi realizada de acordo com o procedimento descrito por Doyle e Doyle (1990) e modificado por Faleiro (2003).

Após a extração, o DNA foi submetido a uma diluição em água de $1: 10$ e quantificado em espectrofotômetro. Em seguida, o DNA foi diluído para uma concentração de trabalho de $10 \mathrm{ng} / \mathrm{mL}$, sendo utilizados cerca de 50 ng de DNA para cada reação de PCR. A relação $\mathrm{A}_{260}$ ' $\mathrm{A}_{280}$ foi utilizada para avaliar a pureza do DNA, e a sua integridade foi determinada em gel de agarose $0,8 \%$.

\section{c) Amplificação e análise do DNA pela técnica de RAPD}

As amostras de DNA foram amplificadas pela técnica de PCR, com 43 primers fabricados pela INVITROGEN ${ }^{\mathrm{TM}}$, constituídos de oligonucleotídios decâmeros e de seqüências arbitrárias. Cada reação continha Tris-KCl (10 mM/50 mM); 2,8 mM de $\mathrm{MgCl}_{2} ; 0,1 \mathrm{mM}$ de cada desoxinucleotídio (dATP, dTTP, dGTP, e dCTP); 0,4 $\mu \mathrm{M}$ de cada primer; $0,5 \mathrm{Un} / \mu \mathrm{L}$ de Taq DNA Polimerase; e $50 \mathrm{ng}$ de DNA. 
Quadro 1 - Relação de indivíduos pertencentes a cada população analisada

Table 1 - List of individuals from each analyzed locality

\begin{tabular}{lc}
\hline Populações & Indivíduos \\
\hline Januária & Ja1, Ja2, Ja3, Ja4, Ja5 \\
Patis & Pa1, Pa2, Pa3, Pa4, Pa5, Pa6, Pa7, Pa8 \\
Mirabela & Mi1, Mi2, Mi3, Mi4, Mi5, Mi6, Mi7 \\
Lontra & Lo1, Lo2, Lo3, Lo4, Lo5, \\
& $\mathrm{Lo6,} \mathrm{Lo7,} \mathrm{Lo8,} \mathrm{Lo9,} \mathrm{Lo10}$ \\
CAA & CA1, CA2, CA3, CA4, CA5, CA6 \\
Jequitaí & Je1, Je2, Je3, Je4, Je5 \\
Morro Alto & MA1, MA2, MA3 \\
\hline
\end{tabular}

Os produtos de amplificação foram separados por eletroforese em gel de agarose 1,2\%, constituído de $10 \mathrm{mg} / \mathrm{mL}$ de brometo-de-etídio imerso em tampão TBE (tris-borato $90 \mathrm{mM}$, EDTA $1 \mathrm{mM}, \mathrm{pH} \mathrm{8,0).} \mathrm{As} \mathrm{bandas}$ de DNA foram visualizadas sob luz ultravioleta e fotografadas com o sistema Vilber Loumart de fotodocumentação.

\section{d) Avaliação dos produtos de amplificação}

A partir da avaliação dos produtos de amplificação (bandas) foi construída uma planilha de dados com informações referentes à presença (1) e ausência (0) de bandas amplificadas. Em seguida, esses dados foram usados para a construção de um dendrograma a partir da similaridade genética de Jaccard, pelo método UPGMA (método da média aritmética não ponderada), por meio do programa PC-ORD (versão 4.01).

\section{e) Caracterização da variabilidade genética}

Para a análise intrapopulacional e também para o conjunto das populações de Dimorphandra mollis, foi utilizado o software POPGENE (YOUNG et al., 2000), com utilização de informações para dados diplóides dominantes. Foram estimados o número de alelos observados (na), o número de alelos efetivos (ne), a diversidade gênica de Nei (1973) $\left(\hat{\mathrm{H}}_{e}\right)$ e o índice de Shannon $\left(\hat{\mathrm{H}}_{o}\right)$.

Para inferir sobre a estrutura genética das populações, foi também realizada a análise de variância de dados moleculares - AMOVA (EXCOFFIER et al., 1992), por meio da decomposição total nas componentes entre e dentro de populações.

\section{RESULTADOS E DISCUSSÃO}

Dos primers testados, somente 29 foram selecionados para o estudo de diversidade genética, por serem mais informativos e produzirem bandas mais nítidas. Foram obtidos 140 produtos de amplificação (bandas), com média de 4,83 bandas por primer, sendo 118 polimórficas e 22 monomórficas (Quadro 2). A Figura 1 ilustra o padrão de bandas obtido em alguns dos indivíduos analisados com a utilização do primer 14 .

Quadro 2 - Seqüência de bases dos primers selecionados que apresentaram melhor padrão de bandas polimórficas e monomórficas

Table 2-Base sequence of the selected primers that presented the best patterns of polymorphic and monomorphic bands

\begin{tabular}{|c|c|c|c|}
\hline \multirow[t]{2}{*}{ Primer } & \multirow{2}{*}{$\begin{array}{c}\text { Seqüência } \\
\text { de Nucleotídeos }\end{array}$} & \multicolumn{2}{|c|}{ Número de Bandas } \\
\hline & & Polimórficas & Monomórficas \\
\hline 1 & CCGCATCTAC & 6 & 1 \\
\hline 3 & CTCACCGTCC & 3 & 0 \\
\hline 4 & TGTCATCCCC & 3 & 2 \\
\hline 5 & GACGGATCAG & 4 & 3 \\
\hline 7 & CCCGCCTTCC & 1 & 0 \\
\hline 8 & ACAGGGCTCA & 3 & 2 \\
\hline 9 & TTACCTGGGC & 4 & 1 \\
\hline 11 & GTGACATGCC & 4 & 4 \\
\hline 12 & AGATGCAGCC & 4 & 1 \\
\hline 13 & ATGGCTCAGC & 8 & 1 \\
\hline 14 & CAGGCCCTTC & 9 & 1 \\
\hline 15 & СTCTTGGGCT & 2 & 0 \\
\hline 16 & ACCACCCGCT & 1 & 4 \\
\hline 17 & ACCCCCACAC & 4 & 0 \\
\hline 18 & AGCGTGTCTG & 2 & 1 \\
\hline 19 & TCACGTCCAC & 6 & 2 \\
\hline 20 & GGCTCATGTG & 8 & 0 \\
\hline 21 & GTCAGGGCAA & 6 & 0 \\
\hline 25 & GCTTGTGAAC & 2 & 0 \\
\hline 26 & GGGACCGTGT & 3 & 0 \\
\hline 27 & GGGTCTCGGT & 1 & 0 \\
\hline 28 & CTGACGTCAC & 4 & 0 \\
\hline 29 & ACGCCCAGGT & 1 & 0 \\
\hline 30 & GTCAGGGGCA & 3 & 0 \\
\hline 34 & AAAGCTGCGG & 6 & 0 \\
\hline 37 & CCTGGGCTTC & 6 & 0 \\
\hline 38 & CCTGGGCTTA & 1 & 0 \\
\hline 39 & CCTGGGCTGG & 3 & 0 \\
\hline 41 & CCTGGGTCCA & 4 & 0 \\
\hline 42 & CCTGGGTTAC & 6 & 0 \\
\hline TOTAL & & 118 & 22 \\
\hline
\end{tabular}

R. Árvore, Viçosa-MG, v.32, n.2, p.355-363, 2008 

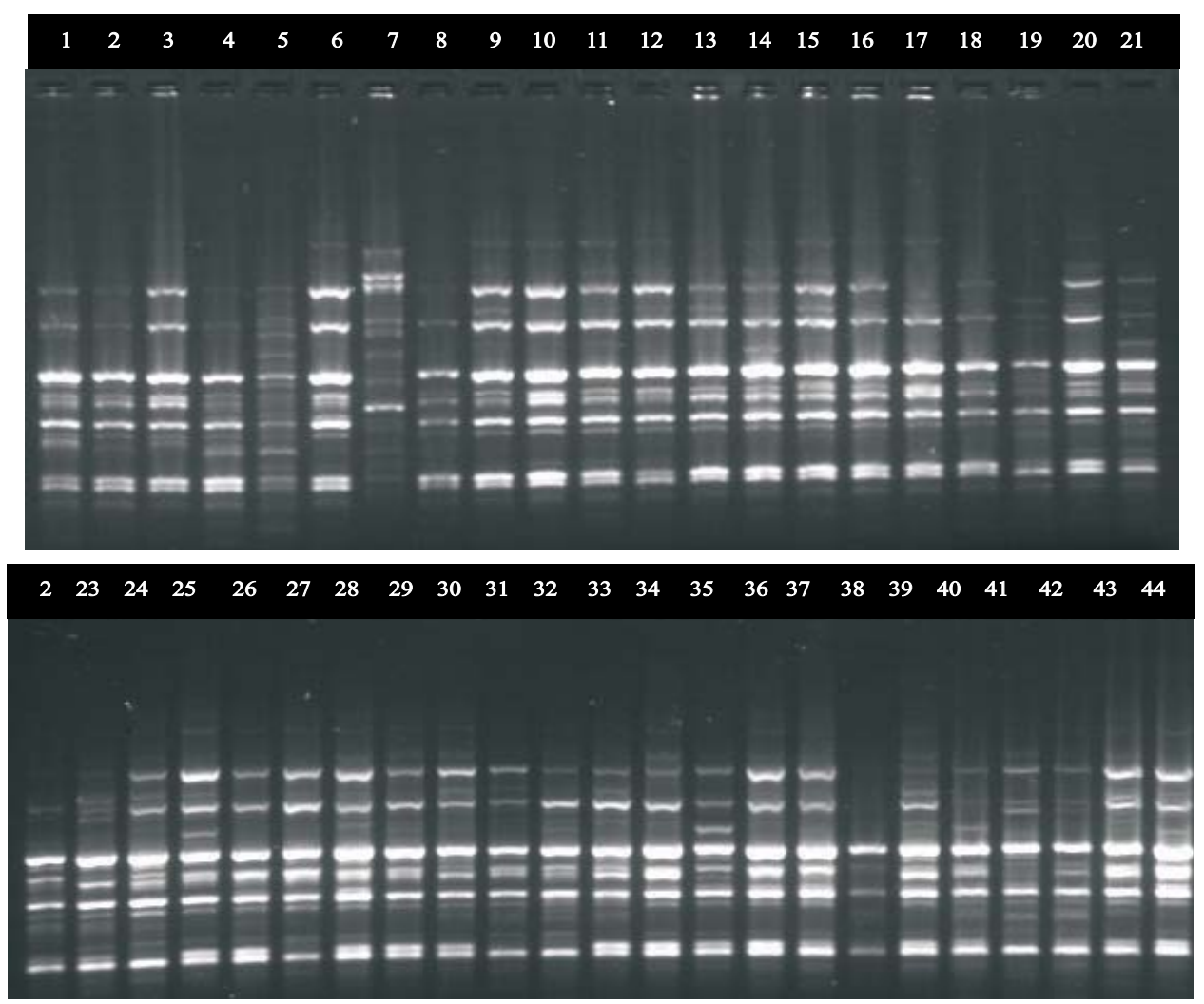

Figura 1 - Padrão de bandas amplificadas por RAPD de todos os indivíduos, com a utilização do primer 14. Figure $1-R A P D$ amplified band patterns of all the individuals, using primer 14 .

Os valores estimados dos índices de diversidade genética encontram-se no Quadro 3. A porcentagem de locos polimórficos observados variou de $44,29 \%$ na população de Jequitaí a $72,86 \%$ para a população de Mirabela. A população de Patis apresentou uma porcentagem de locos polimórficos menor, no valor de $58,57 \%$. A maior porcentagem de locos polimórficos encontrada neste estudo $(72,86 \%)$ foi próxima aos obtidos por Zimback et al. (2004), que relataram estimativas de polimorfismo variando de $90,3 \%$ a 97,3\%, em populações de Trichilia pallida Swatrz, e por Moura (2005), que, estudando cinco populações naturais de Eremanthus erythropapus, encontrou um polimorfismo variando de 90,48 a 92,86 .

Valores menores que o encontrado $(44,29 \%)$ são relatados na literatura, como $7 \%$ observado em Vicia psiformis (BLACK-SAMUELSSON et al., 1997), 20 a $30 \%$ em Acanthus ilicifolius Linn. e Limonium dufourii (LAKSHIMI et al., 1997; PALÁCIOS e GONZÁLESCANDELAS, 1997).

R. Árvore, Viçosa-MG, v.32, n.2, p.355-363, 2008
O número de alelos observados variou de 1,4429 a 1,7286, enquanto o número de alelos efetivos variou de 1,2918 a 1,5227, entre as populações (Quadro 3).

A diversidade genética de $\mathrm{Nei}\left(\hat{\mathrm{H}}_{\mathrm{e}}\right)$ variou de 0,2867 na população de Mirabela a 0,1736 na população de Morro Alto. Os valores de $\left(\hat{H}_{e}\right)$ encontrados neste estudo podem ser considerados próximos, quando comparados com outros trabalhos. Zimback et al. (2004), estudando a espécie Trichilia pallida Swartz, encontraram um valor de $\hat{\mathrm{H}}_{\mathrm{e}}$, variando de 0,27 a 0,33, enquanto Torezan et al. (2005) obtiveram um $\hat{\mathrm{H}}_{\mathrm{e}}$ médio de 0,287 na espécie Aspidosperma polyneuron Muell. Arg. No entanto, as estimativas de $\hat{\mathrm{H}}_{\mathrm{e}}$ deste estudo foram inferiores quando comparadas com as de estudos de populações naturais de Eremanthus erythropapus, em que Moura (2005) obteve um $\hat{\mathrm{H}}_{\mathrm{e}}$ variando de 0,335 a 0,367 e Estopa et al. (2006), $\hat{\mathrm{H}}_{\mathrm{e}}$ com variação entre 0,299 e 0,333. 
Quadro 3 - Diversidade genética da populações naturais de Dimorphandra mollis, amostradas no norte do Estado de Mina Gerais

Table 3 - Genetic diversity in natural populations of Dimorphandra mollis collected in northern Minas Gerais

\begin{tabular}{cccccc}
\hline \multicolumn{7}{c}{ Índices } \\
\hline Populações & $\mathrm{P}$ & $\hat{\mathrm{H}}_{\mathrm{e}}$ & $\hat{\mathrm{H}}_{\mathrm{o}}$ & $\mathrm{na}$ & $\mathrm{ne}$ \\
\hline Januária & 51,43 & $0,2158(0,2245)$ & $0,3111(0,3166)$ & $1,5143(0,5034)$ & $1,3963(0,4324)$ \\
Patis & 58,57 & $0,2452(0,2261)$ & $0,3528(0,3166)$ & $1,5857(0,4962)$ & $1,4542(0,4409)$ \\
Mirabela & 72,86 & $0,2867(0,2120)$ & $0,4166(0,2922)$ & $1,7286(0,4479)$ & $1,5227(0,4144)$ \\
Lontra & 48,57 & $0,2084(0,2250)$ & $0,2993(0,3188)$ & $1,4857(0,5034)$ & $1,3881(0,4246)$ \\
CAA & 45,71 & $0,1933(0,2238)$ & $0,2780(0,3160)$ & $1,4571(0,5018)$ & $1,356(0,4284)$ \\
Jequitaí & 44,29 & $0,2149(0,2423)$ & $0,2998(0,3388)$ & $1,4429(0,5003)$ & $1,4259(0,4712)$ \\
Morro Alto & 47,14 & $0,1736(0,1954)$ & $0,2598(0,2853)$ & $1,4714(0,5028)$ & $1,2918(0,3569)$ \\
\hline Todas & 100 & $0,3033(0,1615)$ & $0,4603(0,2094)$ & $2,0000(0,000)$ & $1,5107(0,3363)$ \\
\hline
\end{tabular}

(): desvio-padrão; $\hat{\mathrm{H}}_{e}$ : diversidade genética de $\mathrm{Nei} ; \hat{\mathrm{H}}_{o}$ : índice de Shannon de diversidade fenotípica; na: número de alelos observados; ne: número de alelos efetivos; $P$ : porcentagem de locos polimórficos.

O índice de Shannon varia de 0 a 1 e considerase que, quanto mais próximo de zero, mais baixa é a diversidade. Os valores estimados para o índice de Shannon $\left(\hat{\mathrm{H}}_{0}\right)$ variaram de 0,2598 a 0,4166 . Os valores do índice de Shannon encontrados neste estudo (Quadro 3) estão próximos daqueles verificados em outras espécies arbóreas, em que foram utilizadas metodologias similares. Lacerda et al. (2001) observaram valores de $\hat{\mathrm{H}}_{0}$ variando de 0,301 a 0,367 em Plathymenia reticulata. $\mathrm{O}$ maior valor alcançado $(0,4166)$ é praticamente idêntico ao encontrado por Torezan et al. (2005), que obtiveram o $\hat{\mathrm{H}}_{0}$ igual a 0,410 em indivíduos adultos de Aspidosperma polyneuron.

A distribuição da variabilidade genética entre e dentro das populações foi calculada de acordo com Nei (1978) (Quadro 4). A divergência genética foi de 0,2883 , demonstrando que $28,83 \%$ da variabilidade genética se encontra entre populações e $71,17 \%$ dentro das populações. De acordo com Yun et al. (1998) e Aagaard et al. (1998), espécies arbóreas, em geral, mostram maior variação genética dentro de populações.

Esses valores são próximos aos encontrados na literatura para outras espécies tropicais. Zucchi (2002) observou $27,3 \%$ de variabilidade genética entre populações de Eugenia dysenterica. Sales et al. (2001) encontraram uma divergência genética de $28,58 \%$ entre populações de Digitalis minor. Wadt (2001) verificou que $28,1 \%$ da diversidade genética está distribuída entre populações de Piper hispidinervium. Zimback et al. (2004), estudando populações de Trichilia pallida, encontraram uma divergência genética inferior à obtida neste estudo, estando $12,5 \%$ dessa variabilidade contida entre suas populações.
Quadro 4 - Parâmetros genéticos populacionais de Dimorphandra mollis. HT: heterozigosidade total; $H S$ : diversidade genética média dentro; GST: divergência gênica entre populações; e $N m$ : fluxo gênico

Table 4-Genetic population parameters for Dimorphandra mollis. HT: Total heterozigosity; HS: Mean genetic diversity within; GST: Genic divergence between populations; and Nm: genic flux

\begin{tabular}{lcccc}
\hline & $\mathrm{H}_{\mathrm{T}}$ & $\mathrm{H}_{\mathrm{S}}$ & $\mathrm{G}_{\mathrm{ST}}$ & $\mathrm{Nm}$ \\
\hline Média & 0,3086 & 0,2196 & 0,2883 & 1,2341 \\
Desvio-padrão & 0,0275 & 0,00188 & & \\
\hline
\end{tabular}

$H T$ : heterozigosidade total; $H S$ : diversidade genética média dentro; GST: divergência gênica entre populações; e $N m$ : fluxo gênico.

A análise de variância molecular (AMOVA) das sete populações também demonstrou que a maior parte de variação genética se encontra dentro de populações $(89,7 \%)$, sendo $10,3 \%$ da variação genética entre populações (Quadro 5). Houve diferenciação genética significativa $(\mathrm{P}<0,001)$ entre as populações.

A heterozigosidade ou diversidade genética é a medida mais importante e a mais utilizada para estimar a variabilidade genética e menos sensível às variações no tamanho da amostra, quando comparada com outras medidas, como a porcentagem de locos polimórficos e o número médio de alelos por locos e possui fácil interpretação em termos genéticos (BROWN e WEIR, 1983). Foi observada um valor de heterozigosidade total (HT) estimada de 0,3086 (Quadro 4), inferior ao encontrado na literatura, como em estudos com Eremanthus erytropappus, realizados por Estopa et al. (2006), em que foram obtidos valores de 0,404 de heterozigosidade total.

R. Árvore, Viçosa-MG, v.32, n.2, p.355-363, 2008 
Quadro 5 - Análise de Variância Molecular (AMOVA) de populações de Dimorphandra mollis (GL= grau de liberdade; $\mathrm{SQ}=$ soma de quadrados)

Table 5 - Analysis of Molecular Variance (AMOVA) of Dimorphandra mollis populations $(G L=$ Degrees of freedom; $S Q=$ Sum of square)

\begin{tabular}{lccccc}
\hline Fonte de Variação & GL & SQ & Componentes de Variância & Porcentagem de Variação & P \\
\hline Entre Populações & 6 & 81,462 & 0,91417 & 10,33 & $<0,001$ \\
Dentro de Populações & 37 & 293,765 & 7,93961 & 89,67 & $<0,001$ \\
\hline Total & 43 & 375,227 & 8,85377 & & \\
\hline
\end{tabular}

De acordo com Wright (1931), valores de fluxo gênico inferiores a 1 indicam isolamento genético. Esse mesmo autor, em 1951, afirmou que valor de fluxo gênico superior a 1 é suficiente para impedir perdas aleatórias de alelos dentro de populações (efeitos de deriva). $O$ valor de fluxo gênico observado na fava d' anta foi de 1,23 , próximo do valor considerado limite pelo autor supracitado como fator importante, quando se pensam em estratégias de conservação da espécie. Em outras espécies, foram observados valores de fluxo gênico maiores e menores que os encontrados na fava d'anta. Perecin (2000), estudando Maytenus aquifolia Mart. e M. ilicifolia Mart. ex. Reiss., encontrou valores de baixos $(0,23)$ a moderados $(6,22)$ de fluxo gênico. Em estudos com canafístula (Peltophorum dubium), Mori (2000) observou um fluxo gênico variando de 3,63 a 3,11. Zimback et al. (2004), estudando populações de Trichilia pallida, verificaram um fluxo gênico de 0,78.

Outros trabalhos relatados na literatura estão de acordo com os resultados observados. Gillies et al. (1999), pesquisando a diversidade genética de Swietenia macrophylla King. por marcadores RAPD, observaram que $87,43 \%$ da variabilidade genética se encontrava dentro de populações, $12,01 \%$ entre populações dentro de regiões e 0,57 entre regiões. Lacerda et al. (2001) constataram que $12,3 \%$ e $16 \%$ da variação genética de Plathymenia reticulata podem ser atribuídos a diferenças entre populações, de acordo com a AMOVA e o índice de Shannon, respectivamente. Moura (2005) verificou, em cinco populações de Eremanthus erytropappus, que $87,62 \%$ da variabilidade se encontra dentro das populações e, apenas $12,38 \%$, entre elas.

Os resultados desTe estudo estão de acordo com o esperado em espécies arbóreas, ou seja, indicam que as populações de Dimorphandra mollis exibem consideráveis níveis de variabilidade genética dentro de suas populações $(89,7 \%)$ e níveis altos de divergência entre elas $(10,3 \%)$.

\section{R. Árvore, Viçosa-MG, v.32, n.2, p.355-363, 2008}

$\mathrm{Na}$ análise de agrupamento entre os indivíduos estudados a partir do índice de similaridade de Jaccard e do critério de aglomeração UPGMA (Figura 2), foram observados oito grupos constituídos por apenas um indivíduo: Mi1 representado pelo indivíduo de Mirabela, Ja4 de Januária, Pa2 de Patis, Pa1 de Patis, Lo10 de Lontra, Mi6 de Mirabela, Mi2 de Mirabela e Ja5 de Januária. Foram observados também dois grupos constituídos de indivíduos de uma mesma localidade: MA1, MA3 (Morro Alto) e Ja2 e Ja5 (Januária), um grupo por três indivíduos de localidades diferentes (Mi7, CA1 e Lo1) e outro grupo representado pelo restante de indivíduos com distâncias genéticas inferiores a $60 \%$.

A avaliação dos dados observados apontou que a divergência genética foi $10,3 \%$ entre populações e $89,7 \%$ dentro das populações, indicando maior variabilidade dentro do que entre as populações de Dimorphandra mollis. A população de Mirabela apresentou maior diversidade genética com maiores valores de índice de diversidade genética $\left(\hat{\mathrm{H}}_{e}\right)$ e de diversidade fenotípica $\left(\hat{\mathrm{H}}_{o}\right)$ e maior porcentagem de locos polimórficos. $\mathrm{O}$ valor de fluxo gênico observado na fava d' anta foi de 1,23. A análise do dendrograma (Figura 2) construído por meio de agrupamento dos indivíduos estudados indicou também maior variabilidade genética dentro das populações do que entre elas, pois não foi observado formação de grupos com indivíduos distribuídos por localidades. O dendrograma confirma também a maior variabilidade da população do Município de Mirabela, pois foi a localidade que apresentou indivíduos em seis diferentes grupos, conforme pode ser observado na Figura 2. A fava d'anta é uma espécie nativa que possui alto valor econômico e, portanto, deve ser preservada. Os dados obtidos são importantes para o monitoramento da situação atual da espécie no Norte do Estado de Minas Gerais e podem ser utilizados como subsídios para o estabelecimento de estratégias de conservação e manutenção da espécie. 
Similaridade genética (\%)

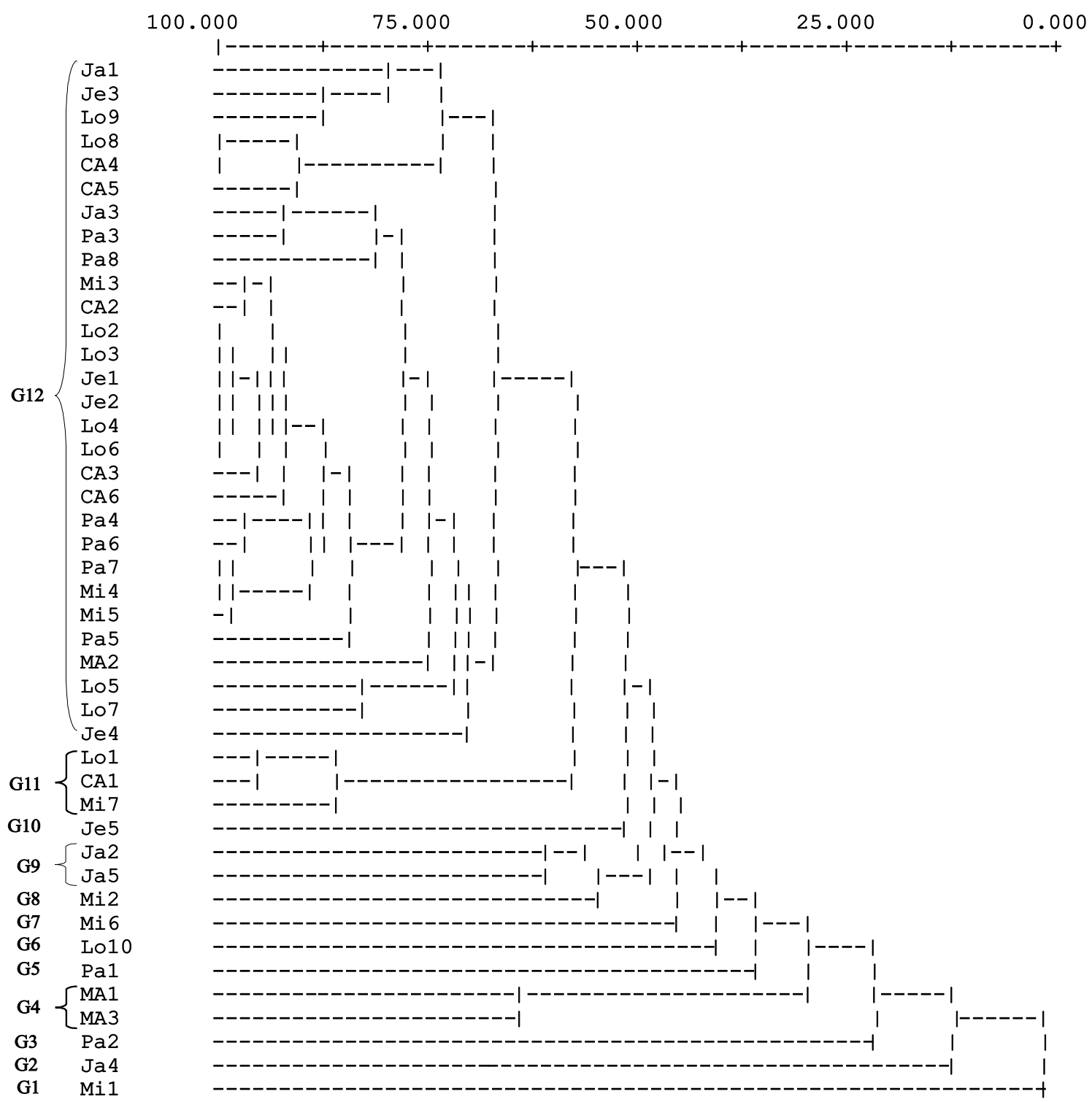

Figura 2 - Dendrograma baseado no coeficiente de similaridade de Jaccard e agrupamento UPGMA de populações de fava d'anta (Dimorphanra mollis Benth.).

Figure 2-Dendrogram based on the Jaccard similarity coefficient and UPGMA grouping offava d'anta populations (Dimorphanra mollis Benth.).

\section{CONCLUSÕES}

A técnica de RAPD mostrou-se eficiente na detecção de polimorfismos entre e dentro das populações de Dimorphandra mollis e permitiu a formação de grupos distintos a partir da análise de agrupamento dos indivíduos das populações naturais analisadas.
A população de Dimorphandra mollis do Município de Mirabela apresentou maior diversidade genética com maiores valores de índice de diversidade genética $\left(\hat{H}_{e}\right)$ de diversidade fenotípica $\left(\hat{\mathrm{H}}_{o}\right)$ e maior porcentagem de locos polimórficos. 
Não foi observado o agrupamento dos indivíduos de uma mesma localidade em um mesmo grupo, mostrando a existência de variabilidade dentro de uma mesma localidade.

A divergência genética foi 10,3\% entre populações e $89,7 \%$ dentro destas, indicando maior variabilidade dentro do que entre as populações de D. mollis.

\section{AGRADECIMENTOS}

À Universidade Estadual de Montes Claros Unimontes, pelo apoio logístico; à Fundação de Amparo à Pesquisa do Estado de Minas Gerais - FAPEMIG, pelo fomento à pesquisa e pelas Bolsas de Incentivo à Pesquisa e ao Desenvolvimento Tecnológico (BIPDT) e de Iniciação Científica concedidas; e ao Conselho Nacional de Desenvolvimento Científico e Tecnológico - CNPq, pelas bolsas de iniciação científica.

\section{REFERÊNCIAS}

AAGAARD, J. E. et al. RAPDs and allozymes exhibit similar levels of diversity and differentiations among populations and races of Douglas-fir. Heredity, v.81, n.1, p.69-78, 1998.

BLACK-SAMUELSSON, S. et al. RAPD and morphological analysis of the rare plant species Vicia psiformis (Fabaceae). Biological Journal of the Linnean Society, v.61, p.325-343, 1997.

BROWN, A. H. D.; WEIR, B. S. Measuring genetic variability in plant populations. In: TANKSLEY, S. D.; ORTON, T. J. (Eds.). Isozymes in plant genetics and breeding. Part A. Amsterdan: Elsevier Science Publishers, 1983. p.73-86.

CAIXETA, R. P. et al. Variação genética em populações de Eucalyptus spp. detectadas por meio de marcadores moleculares. Revista Árvore, v.27, n.3, p.357-363, 2003.

DOYLE, J. J.; DOYLE, J. L. Isolation of plant DNA from fresh tissue. Focus, v.12, n.1, p.13-15, 1990.

ESTOPA, R. A. et al. Diversidade genética em populações naturais de candeia (Eremanthus erytropapus (DC.) MacLeish). Scientia Florestalis, n.70, p.97-106, 2006.

R. Árvore, Viçosa-MG, v.32, n.2, p.355-363, 2008
EXCOFFIER, L. et al. Analysis of molecular variance inferred from metric distances among DNA haplotypes: Application to human mitochondrial DNA data. Genetics, v.131, p.479-491, 1992.

FALEIRO, F. G. et al. Metodologia para operacionalizar a extração de DNA de espécies nativas do cerrado visando a análises moleculares. Brasília: EmbrapaCerrado, 2003. 5p. (Comunicado Técnico, 92)

FERREIRA, M. E.; GRATTAPAGLIA, D.

Introdução ao uso de marcadores moleculares em análise genética. 3.ed. Brasília: Embrapa-Cenargen, 1998. 220p.

GILLIES, A. C. M. et al. Genetic diversity in Mesoamarican populations of mahogany (Swietenia macrophylla), assessed using RAPDs. Heredity, v.83, n.6, p.722-732, 1999.

GIULIANO, I. et al. Identificação de fungos em sementes de Dimorphandra mollis e efeito de diferentes tratamentos. Fitopatologia Brasileira, v.30, n.5, p.553-553, 2005.

GOMES, L. J. Extrativismo e comercialização da fava d'anta (Dimorphandra sp): um estudo de caso na região de cerrado de Minas Gerais. 1998. $158 \mathrm{f}$. Dissertação (Mestrado em Engenharia Florestal) Universidade Federal de Lavras, Lavras, 1998.

LACERDA, C. M. B.; KAGEYAMA, P. Y. Estrutura genética de duas populações naturais de Myracrodruon urundeuva $\mathrm{M}$. Allemão na Região Semi-árida, Brasil. Revista Árvore, v.27, n.2, p.145-150, 2003.

LACERDA, D. R. et al. Genetic diversity and struture of natural populations of Plathymenia reticulata (Mimosoideae), a tropical tree from the Brazilian Cerrado. Molecular Ecology, v.10, n.5, p.1143-1152, 2001.

LAKSHIMI, M. et al. Molecular phylogeny of magroves I. Use of molecular markers in assessing the intraspecific genetic variability in the magrove species Acanthus ilicifolius Linn. (Acanthaceae). Theoretical and Applied Genetics, v.94, n.8, p.1121-1127, 1997.

MORI, E. S. Estrutura genética e populações naturais de canafístula Peltophorum dubium (Spreng) Taub. 2000. 145f. Dissertação (Livre Docência) - Universidade Estadual Paulista, Botucatu, 2000. 
MOURA, M. C. O. Distribuição da variabilidade genética em populações naturais de Eremanthus erythropappus (DC.) MacLeish por isoenzimas e RAPD. 2005. 165f. Tese (Doutorado em Engenharia Florestal) - Universidade Federal de Lavras, Lavras, 2005.

NEI, M. Analysis of genetic diversity in subdivided populations. Proceedings of National Academy of Sciences, v.70, n.12, p.3321-3323, 1973

NEI, M. Estimation of average heterozygosity and genetic distance from a small number of individuals. Genetics, v.89, n.3, p.586-590, 1978.

PALÁCIOS, C.; GONZÁLES-CANDELAS, F. Analysis of population genetic structure and variability using RAPD markers in the endemic and endangered Limonium dufourii (Plumbaginácea). Molecular Ecology, v.6, n.12, p.1107-1121, 1997.

PERECIN, M. B. Diversidade genética em populações naturais de espécies de espinheira-santa, Maytenus aquifolia Mart. e M. ilicifolia Mart. ex. Reiss. (Celastráceae). 2000. 134f. Tese (Doutorado em Agronomia) - Escola Superior de Agricultura "Luiz de Queiroz", Piracicaba, 2000.

SALES, E. et al. Population genetic study in the Balearic endemic plant species Digitalis minor (Scrophulariaceae) using RAPD markes.

American Journal of Botany, v. 88, n.10, p.1750-1759, 2001.

TOREZAN, J. M. D. et al. Genetic variabilithy of pré and post-fragmentation cohorts of Aspidosperma polyneuron Muell. Arg. (Apocynaceae). Brazilian Archives of Biology and Technology, v.48, n.2, p.171-180, 2005.
WADT, H. O. Estrutura genética de populações naturais de pimenta longa (Piper hispidinervum C. DC.) visando seu uso e conservação. 2001. 95f. Tese (Doutorado em Genética e Melhoramento de Plantas) - Escola Superior de Agricultura Luiz de Queiroz, Piracicaba, 2001.

WRIGHT, S. Evolution in mendelian populations. Genetics, v.16, p.97-159, 1931.

WRIGHT, S. The genetical structure of population. Annals of Eugenic, v.15, p.395-420, 1951.

YANAKA, F. Y. et al. Variabilidade genética em populações naturais de Bromus auleticus Tris. ex Ness (Poaceae) com base em isoenzimas e marcadores RAPD. Revista Brasileira de Zootecnia, v.34, n.6, p.1897-1904, 2005.

YOKOZAWA, T. et al. Antioxidant activity of flavones and flavonols in vitro. Phytotherapy Research, v.11, n.6, p.446-450, 1997.

YOUNG, A. et al. Forest conservation genetics. Melbourne: CSIRO Publishing, 2000. 352p.

YUN, R. et al. Study on DNA diversity of Liaodong populations at Dongling mountain region. Acta Botanica Sinica, v.40, p.169-175, 1998.

ZIMBACK, L. et al. Estrutura genética de populações de Trichillia pallida Swartz. (Meliaceae) por marcadores RAPD. Scientia Florestalis, n.65, p.114-119, 2004.

ZUCCHI, M. I. Análise da estrutura genética de Eugenia dysenterica DC utilizando marcadores RAPD e SSR. 2002. 130f. Tese (Doutorado em Genética e Melhoramento de Plantas) - Escola Superior de Agricultura Luiz de Queiroz, Piracicaba, 2002. 